\title{
Investigation of Automotive Detailing Products by Ellipsometry and Contact Angle Analysis
}

\author{
F. Placido, R. Birney* and J. Kavanagh \\ Thin Film Centre, University of the West of Scotland, Paisley PA1 2BE, UK
}

Within the automotive detailing community, there is much discussion focusing on the application of waxes and sealants to enhance and protect paint, and there are a very large number of commercial products on the market. The general idea behind the application of such products is that a wax or sealant layer or layers can increase gloss and "depth of colour", provide protection against degradation by ultraviolet rays and also make it easier to keep the paint surface clean by shedding and repulsion of rain water. In this paper, the performance of several commercially-available automotive waxes and sealants is examined. In the absence of any available published work, we have used ellipsometry to determine the thicknesses of applied wax and sealant layers and have quantified the water beading effect by measuring the contact angles of water with the wax films.

PACS numbers: 81.40.-z, 68.03.Cd, 81.40.Tv, 81.65.Ps

\section{Introduction}

Automotive detailing is a process involving deep cleaning, polishing, waxing and generally enhancing the appearance of road vehicles, sometimes with the intention of exhibiting at car shows. This forms the basis of both a hobby for some and an industry in itself. There are, for instance, many internet forums focusing on auto detailing $[1,2]$.

There are numerous products available for use in auto detailing. Many claims are made in relation to the performance of such products. However, most of the claims made on behalf of particular products lack any substantive scientific evidence, and are based on subjective impressions of the appearance of the waxed paint, sometimes backed up by statements about the ability of the waxed surface to cause water to bead and how long this effect lasts [3]. Some detailers claim that it is possible to build up multiple layers of products for enhanced performance.

In this paper, we have examined four waxes and sealants. The film thickness has been measured by ellipsometry, using a single layer model as a start-point, and the water-repellent qualities of the products have been quantified by measurement of contact angle.

\section{Experimental details}

\subsection{Application of products to substrates}

Four commercially-available automotive waxes and sealants were applied to polished silicon wafer substrates (to simulate a planarised, automotive paint finish surface), according to each of the manufacturers' instructions, using clean new microfibre cloths for each product to avoid any cross-contamination (Table I).

\footnotetext{
* corresponding author; e-mail: ross.birney@uws.ac.uk
}

TABLE I

General descriptions of the products under investigation.

\begin{tabular}{l|l|l}
\hline \hline $\begin{array}{c}\text { Wax/ } \\
\text { Sealant } \\
\text { number }\end{array}$ & \multicolumn{1}{|c|}{ Type of product } & Contents (not exhaustive) \\
\hline 1 & spray wax & $\begin{array}{l}\text { carnauba wax, UV absorber } \\
\text { compounds, solvent }\end{array}$ \\
\hline 2 & $\begin{array}{l}\text { spray sealant (to be ap- } \\
\text { plied on top of wax coat } \\
\text { or bare paint surface) }\end{array}$ & $\begin{array}{l}\text { synthetic polymers, water } \\
\text { repellent, strong solvent car- } \\
\text { rier }\end{array}$ \\
\hline 3 & $\begin{array}{l}\text { spray sealant } \\
\text { synthetic polymers, UV ab- } \\
\text { sorbers, solvent }\end{array}$ \\
\hline 4 & $\begin{array}{l}\text { quick detailer (QD) } \\
\text { spray }\end{array}$ & synthetic polymers, solvent \\
\hline
\end{tabular}

\subsection{Water contact angle}

The contact angle $\Theta$, the angle formed between the film surface and a droplet of deionised water in contact with one another at the solid/liquid boundary, is a good indication of the hydrophobicity or hydrophilicity of a surface, and can be measured directly [4] (Fig. 1).

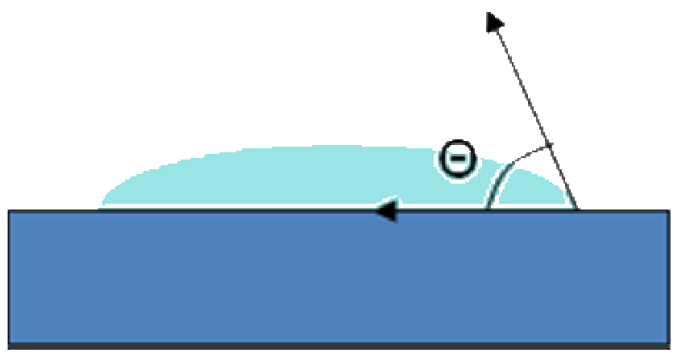

Fig. 1. Contact angle between sessile drop of water and the waxed substrate.

In terms of automotive detailing, a highly hydrophobic surface is desirable, and will result in rain water be- 
ing strongly repelled by the waxed paint surface, and a "beading" effect. In order to quantify this effect, the water contact angles of the commercial waxes and sealants were measured shortly after application, and then at regular intervals to assess the persistence of any water repelling effects. The contact angles were measured using a KSV Instruments CAM200 goniometer.

\subsection{Ellipsometric measurements}

The silicon substrates, coated with the individual waxes and sealants, were examined by spectroscopic ellipsometry $\left(70^{\circ}\right.$ angle of incidence) in order to determine the optical properties and thickness of the residual coating remaining after application and buffing or drying (according to manufacturers' instructions). A HORIBA Jobin-Yvon UVISEL ellipsometer with DeltaPsi 2 software was used, in the spectral range $260-730 \mathrm{~nm}$.

As the wax and sealant films would be expected to have refractive indices of approximately 1.4, the ellipsometric spectra of the films were fitted using a single-layer model, assuming the waxes to have the same dielectric function as that of silicon dioxide for the purpose of calculation of film thickness.

\section{Results}

Figures 2-5 show the measured and calculated values of ellipsometric parameters $I_{\mathrm{s}}$ and $I_{\mathrm{c}}$, derived from the Fourier components of the detected signal and related to the parameters $\psi$ and $\Delta[5]$, as follows:

$$
\begin{aligned}
& I_{\mathrm{s}}=\sin 2 \Psi \sin \Delta, \\
& I_{\mathrm{c}}=\sin 2 \Psi \cos \Delta .
\end{aligned}
$$

The data was fitted using the iterative fitting algorithm, to minimize the value of $\chi^{2}$, the merit function which quantifies the difference between the measured and calculated ellipsometric values, defined here as

$$
\begin{aligned}
\chi^{2} & =\frac{1}{N-M-1} \\
& \times \sum_{i}^{N}\left[\left(\frac{I_{\mathrm{s}}^{\exp }-I_{\mathrm{s}}^{\mathrm{cal}}}{\sigma_{I_{\mathrm{s}}}}\right)^{2}+\left(\frac{I_{\mathrm{c}}^{\mathrm{exp}}-I_{\mathrm{c}}^{\mathrm{cal}}}{\sigma_{I_{\mathrm{c}}}}\right)^{2}\right],
\end{aligned}
$$

where $I_{x}^{\text {exp }}$ are the experimentally-determined values, $I_{x}^{\text {cal }}$ are the values calculated using the model, $\sigma_{I_{x}}$ are the point-wise experimental errors of the respective measured values, $N$ is the number of data points, and $M$ is the number of unknown model parameters [6].

Table II shows the results of the contact angle measurements on the waxed substrates, and the residual film thicknesses calculated from the ellipsometric fitting.

\section{Conclusions}

It is clear from our initial experiments that there is significant variation in the performance of the different sealants and waxes; initial water contact angles span a range of $71.17^{\circ}$ to $94.85^{\circ}$. One week after application, relative changes in mean contact angle are not significant,

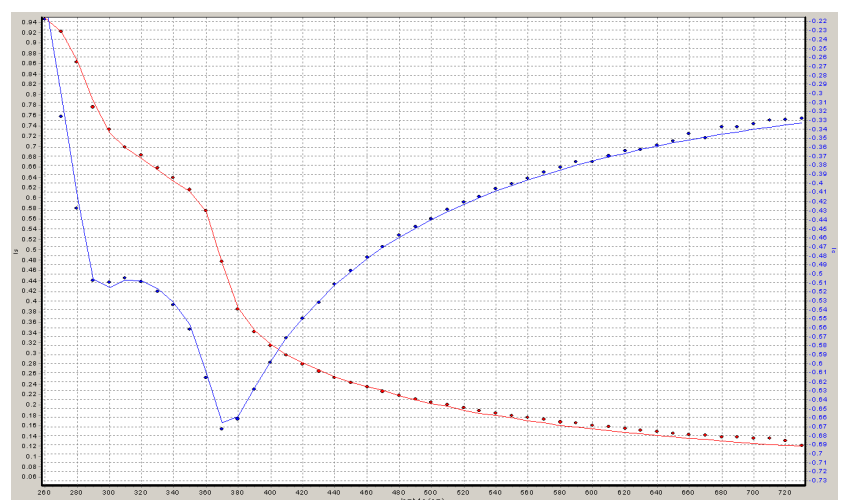

Fig. 2. (Wax 1) Measured values and fit $-I_{\mathrm{S}}$ and $I_{\mathrm{C}}$ vs. $\lambda\left(\chi^{2}=0.3594\right)$.

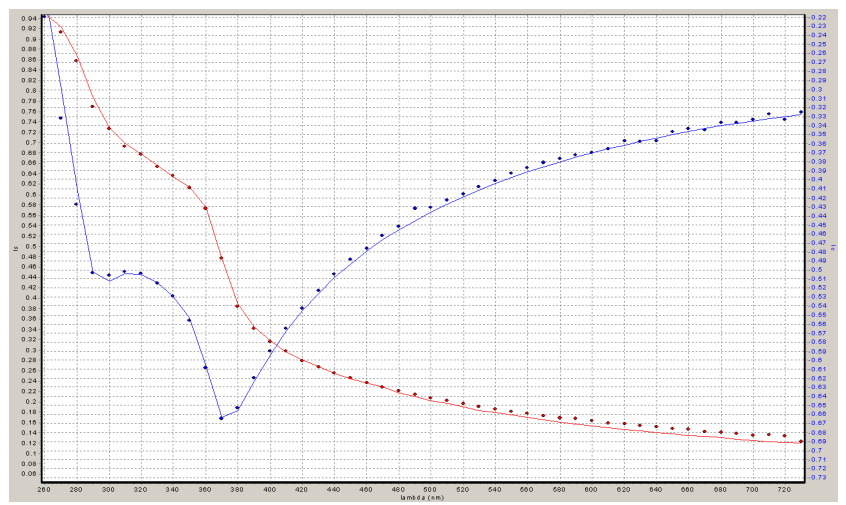

Fig. 3. (Wax 2) Measured values and fit $-I_{\mathrm{s}}$ and $I_{\mathrm{c}}$ vs. $\lambda\left(\chi^{2}=0.6146\right)$.

indicating that the water-repellent effect lasts at least for 1 week. It is possible that more significant changes in contact angle may be observed over a longer time interval.

There are also significant differences to be found in residual coating thickness after application across the various products (from around $44-77 \AA$ ). (It should be

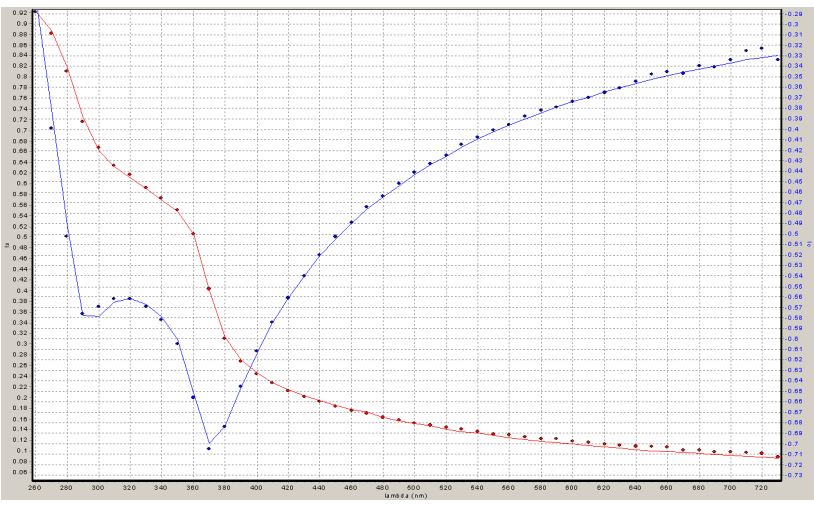

Fig. 4. (Wax 3/sealant) Measured values and fit $-I_{\mathrm{S}}$ and $I_{\mathrm{c}}$ vs. $\lambda\left(\chi^{2}=0.2389\right)$. 


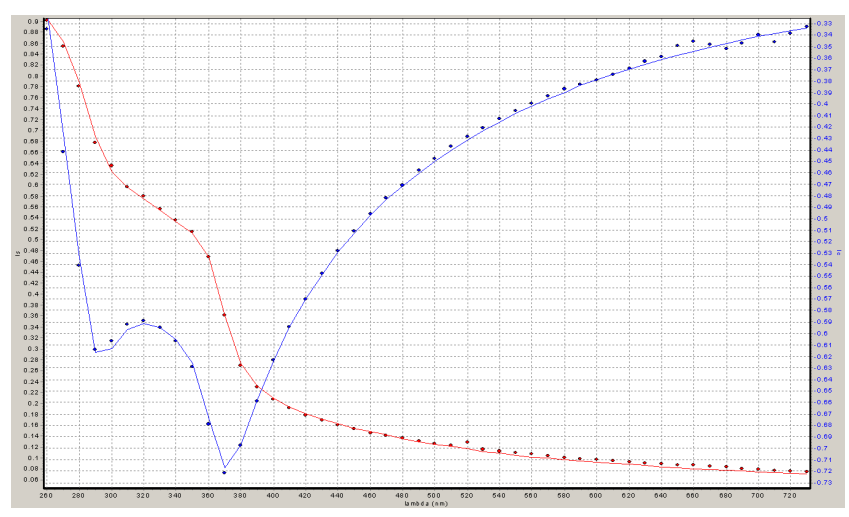

Fig. 5. (Wax 4) Measured values and fit $-I_{\mathrm{S}}$ and $I_{\mathrm{c}}$ vs. $\lambda\left(\chi^{2}=0.2357\right)$.

TABLE II

Residual film thickness after manufacturer-prescribed application, and water contact angle at $t=0$ and $t=1$ week.

\begin{tabular}{c|c|c|c}
\hline \hline Sample ID & $\begin{array}{l}\text { Film thickness } \\
\text { after prescribed } \\
\text { application } \\
\text { process }[\AA]\end{array}$ & $\begin{array}{l}\text { Water contact } \\
\text { angle (initial) } \\
\text { [degrees] }\end{array}$ & $\begin{array}{l}\text { Water contact } \\
\text { angle (storage } \\
\text { time = 1 week) } \\
\text { [degrees] }\end{array}$ \\
\hline wax 1 & $77.607 \pm 0.598$ & $94.85 \pm 1.07$ & $97.56 \pm 2.25$ \\
wax 2 & $77.318 \pm 0.779$ & $91.97 \pm 0.78$ & $90.93 \pm 0.19$ \\
wax 3/ & $55.564 \pm 0.452$ & $72.98 \pm 0.80$ & $71.63 \pm 1.70$ \\
sealant & $71.17 \pm 2.14$ & $71.67 \pm 0.48$ \\
wax 4 & $44.907 \pm 0.435$ & &
\end{tabular}

noted, however, that the silicon dioxide model used for the fitting here is merely a starting point, and a more sophisticated model should be developed.) Although it would be expected that coating thickness is somewhat dependent on application technique, we have found good reproducibility if the manufacturers' instructions are followed exactly and ambient conditions are kept fairly constant.

A final point to note is that the effects of multiple layer application have not been considered as yet.

\section{References}

[1] http://www.autopia.org/forum/index.php .

[2] http://www.detailuniversity.com/forums/ .

[3] http://www.web-cars.com/detail/wax.php .

[4] D.W. Kwok, A.W. Neumann, Adv. Colloid Interface Sci. 81, 167 (1999).

[5] Y. Shim, W. Okada, N. Mamedov, Thin Solid Films 509, 137 (2006).

[6] H.G. Tompkins, E.A. Irene, Handbook of Ellipsometry, Springer, Heidelberg 2005, p. 264. 